\title{
Erratum to: Dimorphic histopathology of long-standing childhood-onset diabetes
}

\author{
R. Gianani • M. Campbell-Thompson • S. A. Sarkar • \\ C. Wasserfall • A. Pugliese • J. M. Solis • S. C. Kent • \\ B. J. Hering - E. West • A. Steck • S. Bonner-Weir • \\ M. A. Atkinson • K. Coppieters • M. von Herrath • \\ G. S. Eisenbarth
}

Published online: 5 June 2010

(C) Springer-Verlag 2010

\section{Erratum to: Diabetologia \\ DOI 10.1007/s00125-009-1642-y}

Unfortunately there were some errors in this paper, necessitating several corrections. For clarity, the corrected figure legends are written out in full.

Results: In the second paragraph of the Results section it is stated that, of the pancreases from childhood-onset diabetic patients with diabetes duration of greater than 5 years, no insulin-positive cells were found within the islets of $70 \%$ (14 of 20), whereas this should read 'patients with a duration of diabetes of at least 1 year'.

Discussion: In the first paragraph of the Discussion section it is stated that one of three pancreases with regions of insulin-deficient islets plus islets with beta cells was from a

The online version of the original article can be found at http://dx.doi. org/10.1007/s00125-009-1642-y.

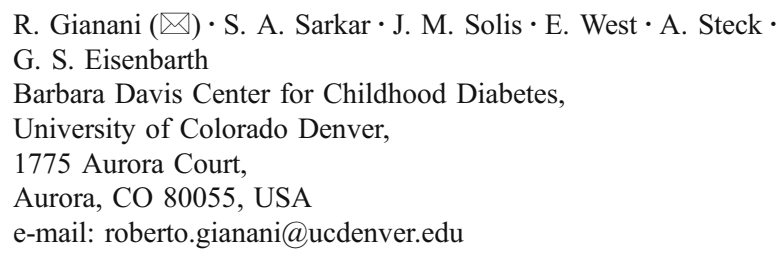

M. Campbell-Thompson · C. Wasserfall • M. A. Atkinson Department of Pathology, University of Florida at Gainesville, Gainesville, FL, USA

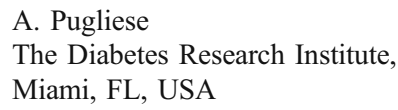

patient with 1 year disease duration with onset at age 12, whereas it should read 'onset at age 11'.

Fig. 4 Immunofluorescence staining for survivin, insulin and glucagon in the pancreas of patients with pattern A beta cell loss (patient DM13) (a-f), pattern B beta cell loss (patient DM18) (g-l) and in a normal control (C10) $(\mathbf{m}-\mathbf{r})$. Pseudocolour grey indicates insulin $(\mathbf{a}, \mathbf{g}, \mathbf{m})$, glucagon $(\mathbf{b}, \mathbf{h}, \mathbf{n})$ or survivin $(\mathbf{c}, \mathbf{i}, \mathbf{o})$. d, j, p Insulin (pseudocoloured grey), survivin (pseudocoloured green). $\mathbf{e}, \mathbf{k}, \mathbf{q}$ Glucagon (pseudocoloured grey), survivin (pseudocoloured green). f, $\mathbf{l}, \mathbf{r}$ Merged composite images (insulin pseudocoloured blue, glucagon pseudocoloured red, survivin pseudocoloured green). Scale bars $50 \mu \mathrm{m}$. a-f Survivin staining is present in a subset of beta cells here, but not in other pancreases $(\mathbf{g}-\mathbf{l}, \mathbf{m}-\mathbf{r})$. The smaller percentage of stained beta cells seen in comparison to Fig. 5
S. C. Kent

Center for Neurologic Diseases,

Brigham and Women's Hospital Harvard Medical School, Boston, MA, USA

\section{B. J. Hering}

The Schulze Diabetes Institute, University of Minnesota, Minneapolis, MN, USA

S. Bonner-Weir

Joslin Diabetes Center, Harvard Medical School,

Boston, MA, USA

K. Coppieters $\cdot$ M. von Herrath

La Jolla Institute of Allergology and Immunology,

La Jolla, CA, USA 
probably reflects lower sensitivity of the immunofluorescence staining and differential producing of survivin by individual beta cells. In the pancreas of patient DM13 (a-f), survivin (c) is produced by beta and alpha cells, while in pancreases of patient DM18 (i) and C10 (o) beta cells do not produce survivin

Fig. 6 Beta cell islet area (expressed as percentage of mean beta cell islet area in normal controls) in the pancreases of long-standing childhood-onset diabetic patients with complete beta cell loss (black diamonds), patients with childhood-onset diabetes but the presence of residual beta cells with pattern A (black squares) or pattern B (black triangles), and patients with type 2 diabetes (grey diamonds) and normal controls (grey triangles)

Fig. 7 Percentage of islets containing insulin-positive cells in the pancreases of patients with childhood-onset diabetes with complete beta cell loss (black squares), patients with childhood-onset diabetes but the presence of residual beta cells with pattern A (black triangles) or pattern B (white squares), patients with adult-onset type 2 diabetes (white triangles) and normal controls (black circles). Only three (of six) pancreases of patients with childhood-onset diabetes had residual beta cell area as well as insulin-deficient islets (i.e. islets without any insulin-positive cells) (pattern A). The remaining three pancreases of patients with childhoodonset diabetes with residual beta cells (as well as the pancreases of patients with a clinical history of type 2 diabetes) did not contain any insulin-deficient islets (pattern B). In the chart these individuals are shown as having $100 \%$ of their islets containing insulin-positive cells. The majority (14 of 20) of the pancreases of childhood-onset diabetic patients contained insulin-deficient islets, including the three patients who also had islets with insulin-positive cells. All these patients, except for the three with residual beta cells, are shown as having $0 \%$ of their islets containing insulin-positive cells 